\title{
Removal of 1,4-Dioxane from Wastewater by Copper Oxide Catalyzed WAO with Mild Condition
}

\author{
Quyuan Wang ${ }^{1}$, Runtian $\mathrm{He}^{2}$, Jing $\mathrm{Xu}^{* 2}$ and Fangming Jin*2,3 \\ ${ }^{1}$ China-UK Low Carbon College, Shanghai Jiao Tong University, 3 Yinlian Road, 201306, Shanghai, P. R. China \\ ${ }^{2}$ School of Environmental Science and Engineering, State Key Lab of Metal Matrix Composites, Shanghai Jiao Tong University, 800 \\ Dongchuan Road, Shanghai 200240, P. R. China \\ ${ }^{3}$ Shanghai Institute of Pollution Control and Ecological Security, Shanghai 200092, China
}

\begin{abstract}
Dioxane is a contaminant of emerging concern that is classified by the U.S. Environmental Protection Agency as a likely human carcinogen. Moreover, 1,4-dioxane easily migrates to groundwater due to its high solubility in water and hard to be biodegraded or removed by traditional water treatment technology. Therefore, it is indispensable to develop new methods and technologies to dispose of 1,4-dioxane in the wastewater. Herein, this study presented catalytic wet air oxidation (CWAO) with $\mathrm{CuO}$ as a catalyst and $\mathrm{O}_{2}$ as an oxidant to treat 1,4-dioxane and investigated the influence of reaction conditions, including temperature, reaction time, oxygen content, catalyst addition and $\mathrm{pH}$, on the degradation of 1,4-dioxane. The highest degradation rate $(R)$ of 1,4-dioxane was $95.8 \%$ when the optimal reaction conditions were at $200{ }^{\circ} \mathrm{C}$ and $1 \mathrm{MPa}$ $\mathrm{O}_{2}$ for $60 \mathrm{~min}$ with $5 \mathrm{mmol} \mathrm{CuO}$ added. If the effect of $\mathrm{Cu}^{2+}$ dissolution was not considered, the $R$ of 1,4-dioxane is up to $99.8 \%$ was achieved at an acidic condition $(\mathrm{pH}=3)$ with $2 \mathrm{mmol} \mathrm{CuO}$ added.
\end{abstract}

\section{INTRODUCTION}

1,4-Dioxane is miscible in water, essentially nonvolatile when dissolved in water, not well adsorbed by activated carbon, not readily biodegraded and not well eliminated by reverse osmosis at concentrations relevant to drinking water standard[1]. Whereas an effective method to dispose of 1,4-dioxane is advanced oxidation processes (AOPs), which produces free radicals that reacts with organic pollutants quickly. Among all kinds of AOPs, $\mathrm{O}_{3} /$ $\mathrm{H}_{2} \mathrm{O}_{2}$ system [2], ultra-violet (UV) based AOP, such as $\mathrm{UV} / \mathrm{H}_{2} \mathrm{O}_{2}$ [3-5], UV/ $\mathrm{S}_{2} \mathrm{O}_{8}{ }^{2-}[3,6], \mathrm{UV} / \mathrm{HOCl}[7,8]$, $\mathrm{UV} / \mathrm{NH}_{2} \mathrm{Cl} \quad[8, \quad 9], \quad \mathrm{UV} / \mathrm{Fe}(\mathrm{II}) / \mathrm{H}_{2} \mathrm{O}_{2} \quad$ [10], UVvis/ferrioxalate $/ \mathrm{H}_{2} \mathrm{O}_{2}$ [11], and the photoelectro-peroxone process [12] have been widely studied [13]. Although these AOPs has a good efficacy on degrading 1,4-dioxane, some obstacles still exist including expensive oxidants, metal salts as secondary pollutants, highly ecotoxic byproducts and low efficiency [14]. In addition, almost all methods removing 1,4-dioxane from wastewater are hard to reach the standard of 1,4-dioxane-concentration $<0.5$ ppm.

Catalytic wet air oxidation (CWAO) has been applied as one of the AOPs to treat bio-toxic organic wastewater treatment for many years [15-17]. In this process, organic pollutants are almost oxidized into carbon dioxide and water at high temperature $\left(150-375^{\circ} \mathrm{C}\right)$ and pressure $(0.5-$ $20 \mathrm{MPa}$ ) with oxygen as an oxidant. It is known to all that oxygen is cheap and easily available, which could replace the expensive and unstable oxidant. Furthermore, CWAO process is extremely clean without any harmful and toxic by-products. Since, the catalyst is the heart of CWAO process, the selection of the catalyst is important for the feasibility of CWAO. Although, homogenous catalysts and noble metals have very good activity towards oxidation of 1,4-dioxane, they are very expensive and easily poisoned by halogens and sulphur group containing compounds.

In recent years, metal-oxide catalysts such as copper, iron, manganese, and nickel oxides have been widely used for the treatment of various organic compounds. Santos et al. studied CWAO of phenol using copper-oxide catalyst at $127-160{ }^{\circ} \mathrm{C}$ and $8-16$ bar pressure, and phenol mineralization of $77 \%$ was obtained. The leaching of copper was minimized using sodium bicarbonate and the intermediates formed in CWAO effluent were found to be less toxic than phenol. Kim and $\mathrm{Ihm}$ reported optimum copper loading of $20 \mathrm{wt} \%$ for $\mathrm{CuO}_{\mathrm{x}} / \mathrm{TiO}_{2}$ catalyst for CWAO of phenol [18]. However, few researches reported the CWAO process used on degradation of 1,4-dioxane. Hence, in this work, we present a new method using CWAO process to decompose 1,4-dioxane from wastewater with copper oxide catalyst and $\mathrm{O}_{2}$ as an oxidant.

\section{MATERIAL AND METHODS}

\subsection{Materials}

$\mathrm{MnO} 2, \mathrm{Ag} 2 \mathrm{O}, \mathrm{MoO} 3, \mathrm{SiO} 2$ and 1,4-dioxane (99.99 \%) were obtained from Sinopharm Chemical Reagent Co. Ltd.; $\mathrm{CuO}(99.99 \%, 10 \mu \mathrm{m}), \mathrm{CeO} 2, \mathrm{CoO} 3, \mathrm{TiO} 2$ were

\footnotetext{
*Corresponding author: ruozixj@sjtu.edu.cn, fmjin@sjtu.edu.cn
} 
brought from Shanghai Macklin Biochemical Co., Ltd; formic acid (for mass spectrometry, $98 \%$ ) from SigmaAldrich (Shanghai) Trading Co., Ltd.; gaseous O2 $(>99.99 \%)$ and N2 (>99.99\%) both from Shanghai PolyGas Technology Co. Ltd. All of the raw materials used in the experiment were in analytical grade without further purification. The solvent used in the experiment is distilled water.

\subsection{Experimental facilities}

In this experiment, a six-linked high-temperature parallel reactor with an effective volume of $7 \mathrm{ml}$ was used as the reactor. It is convenient for the reaction system to add oxygen at different partial pressures and ensure the stability of reaction temperature and time. The reactor can carry out up to 6 experiments at the same time, with the uniform temperature and pressure. It can also control stirring speed, air intake and air bleed.

\subsection{Analytical methods}

The crystalline phases in the solid samples were detected by X-Ray Diffraction (XRD) (Shimadzu, LabXRD-6100, scanning speed: $2^{\circ} \min -1,2 \theta$ ranges: $\left.5-80^{\circ}\right)$. The morphology of the $\mathrm{CuO}$ particles was observed by scanning electron microscope (SEM). The X-ray photoelectron spectroscopy (XPS) spectra were obtained with incA-Max 80 type energy dispersive X-ray spectrometer of Oxford Company, which was used to analyze the changes of the valence states of elements before and after the reaction of $\mathrm{CuO}$. The Fourier Transform Infrared Spectra (FTIR) of $\mathrm{CuO}$ before and after reaction of 1,4-dioxane were observed. The concentrations of 1,4-dioxane and by-products were measured by High Performance Liquid Chromatograph (HPLC) and Gas Chromatography- Flame Ionization Detector (GC-FID) equipped with a HP- INNOWAX polyethylene glycol capillary column. The by-products were detected by GC-MS (Agilent7890A GC system, 5975C inert MSD with Triple-Axis Detector) equipped with the same column as the GC-FID. The degradation rate of 1,4-dioxane $(\mathrm{R})$ was calculated according to the following equation:

$$
R=\frac{C}{C_{0}} \times 100 \%
$$

where $\mathrm{C}$ and $\mathrm{C} 0$ are the molar concentrations after and before the reaction, respectively.

\subsection{Experimental procedure}

All reactions were conducted in a $316 \mathrm{~L}$ high-pressure hydrothermal reactor with magnetic stirring and a charge valve, and the internal volume of reactor is $7 \mathrm{~mL}$. The certain amount of 1,4-dioxane (1000 ppm) solution (3 mL e.g.) and catalyst $(1 \mathrm{mmol}$ e.g.) were added into the reactor first, and then the reactor was purged with $\mathrm{O} 2$ for $1 \mathrm{~min}$. After the reactor filled with a certain pressure (1 $\mathrm{MPa}$ e.g.) of oxygen, it was placed at a heater instrument at the desired reaction temperature $(200 \mathrm{oC}$ e.g. $)$ and time (60 min e.g.) with continuous stirring. Finally, after reaction, the reactor was cooled down to the room temperature. Liquid samples were collected and filtered with $0.22 \mu \mathrm{m}$ Syringe Filter and transferred to a vial for subsequent analysis. The solid samples were washed by deionized water several times and dried in vacuum for subsequent analysis.

\section{RESULTS AND DISCUSSION}

\subsection{Screening of metal oxides}

To investigate the degradation performance of 1,4dioxane by CWAO with different metal oxides, $100 \mathrm{mg} / \mathrm{L}$ of 1,4-dioxane solution and $1 \mathrm{mmol}$ of metal oxide were added into the reactor, and the filling amount was $40 \%$. The reaction was carried out at $200 \mathrm{oC}, 1 \mathrm{MPa} \mathrm{O} 2$ for 60 min, and the results were shown in the Figure 1. Without any metal oxide addition, hydrothermal environment had a weak effect on removal of 1,4-dioxane that the $\mathrm{R}$ was only $7.78 \%$. The R increased by $10-30 \%$ after adding different metal oxides. Particularly, $\mathrm{CuO}$ showed a good improvement effect on $\mathrm{R}$ reaching $34.68 \%$. Because of its good catalytic performance, copper oxide was chosen as the catalyst for this experiment.

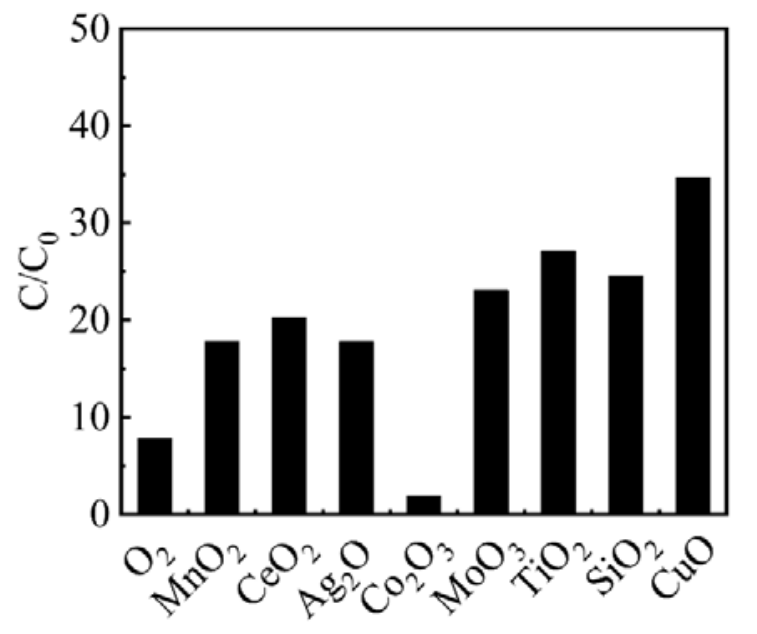

Figure 1. Effects of different metal oxides on the degradation of 1,4-dioxane by wet air oxygen oxidation. (1,4-dioxane: 100 $\mathrm{mg} / \mathrm{L}$; temperature: $200{ }^{\circ} \mathrm{C}$; time: $1 \mathrm{~h}$; $\mathrm{O}_{2}: 1 \mathrm{MPa}$; oxides: 1 mmol)

\subsection{Catalyst characterization}

In the SEM analysis, the $\mathrm{CuO}$ powder showed the typical particle morphology with a spherical shape in Figure 2. There are small particles appearing on the surface after the reaction. 

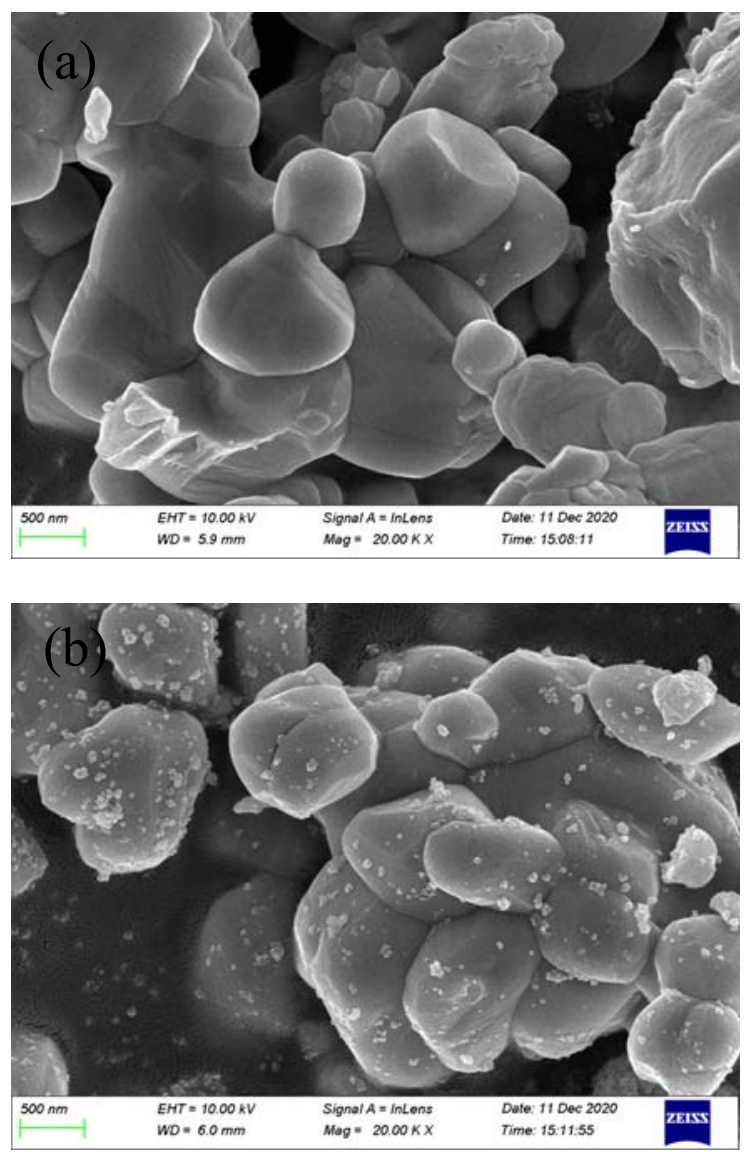

Figure 2. SEM images of $\mathrm{CuO}$ (a) before and (b) after the reaction. (temperature: $200{ }^{\circ} \mathrm{C}$; time: $1 \mathrm{~h} ; \mathrm{O}_{2}: 1 \mathrm{MPa} ; \mathrm{CuO}: 1$ $\mathrm{mmol}$ )

The XRD patterns of $\mathrm{CuO}$ samples before and after the reaction are given in Figure 3. Prominent peaks at the diffraction angle $(2 \theta) 35.4^{\circ}, 38.5^{\circ}$ and $48.8^{\circ}$ refer to $(0,0,2)$, $(2,0,0)$ and $(2,0,-2)$ lattice planes of monoclinic $\mathrm{CuO}$ (JCPDS No. 48-154), respectively [19]. The two samples exhibited a similar diffraction pattern and the half-peak

(a)

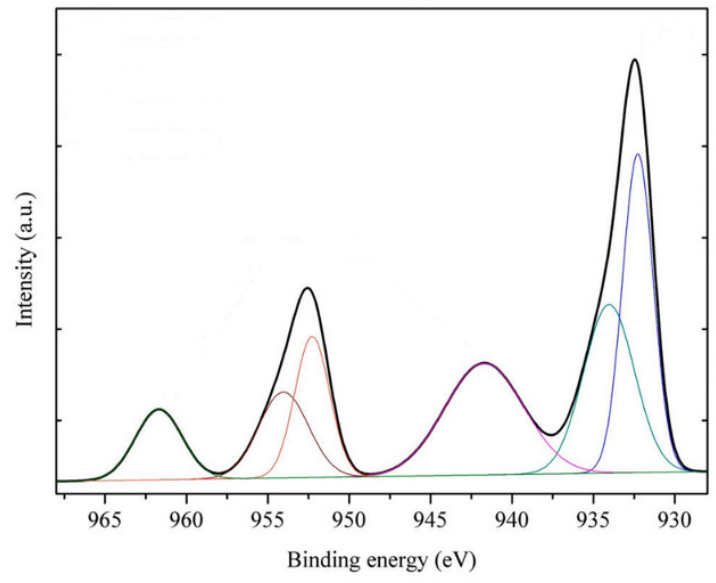

width, which means the structure and crystallinity of the $\mathrm{CuO}$ did not change after reaction.

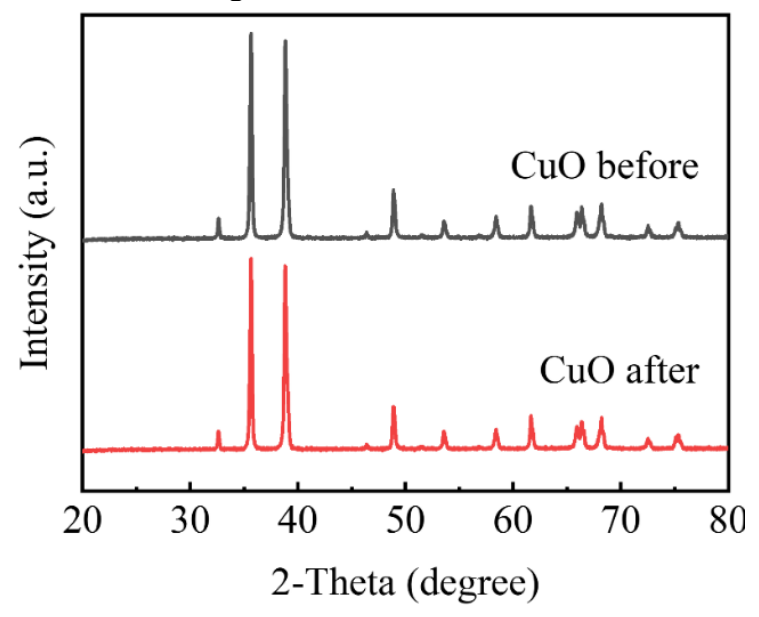

Figure 3. $\mathrm{XRD}$ patterns of $\mathrm{CuO}$ before and after the reaction. (temperature: $200{ }^{\circ} \mathrm{C}$; time: $1 \mathrm{~h}$; $\mathrm{O}_{2}: 1 \mathrm{MPa}$; $\mathrm{CuO}: 1 \mathrm{mmol}$ )

The oxidation states of $\mathrm{Cu}$ in the $\mathrm{CuO}$ before and after the catalytic oxidation of 1,4-dioxane was investigated by XPS, which is shown in Figure 4. The peaks located at 933.4 and $953.2 \mathrm{eV}$ can be attributed to $\mathrm{Cu} 2 \mathrm{p} \mathrm{3/2}$ and $\mathrm{Cu}$ $2 \mathrm{p} 1 / 2$ of $\mathrm{CuO}$, respectively. In addition, shake-up satellite peaks located at 940.6, 943.2 and $961.8 \mathrm{eV}$ may be due to the open $3 \mathrm{~d} 9$ shell of $\mathrm{Cu} 2+$ [20]. The XPS peaks located at $932.6 \mathrm{eV}$ and $952.4 \mathrm{eV}$ are the characteristic signals of $\mathrm{Cu}(\mathrm{I})$ for $\mathrm{Cu} 2 \mathrm{p} 3 / 2$ and $\mathrm{Cu} 2 \mathrm{p} 1 / 2$, respectively [21]. Since no diffraction peaks belonging to $\mathrm{Cu} 2 \mathrm{O}$ were detected in the XRD pattern (Figure 3 (b)), the $\mathrm{Cu} 2 \mathrm{O}$ species is probably restricted to the surface. For the $\mathrm{CuO}$ sample after catalytic oxygen oxidation the peaks at 934.2 and $954.2 \mathrm{eV}$ shifted to lower binding energy when compared to the sample before the reaction, which means that more $\mathrm{Cu}+$ was presented on the $\mathrm{CuO}$ surface after oxygen oxidation[22].

(b)

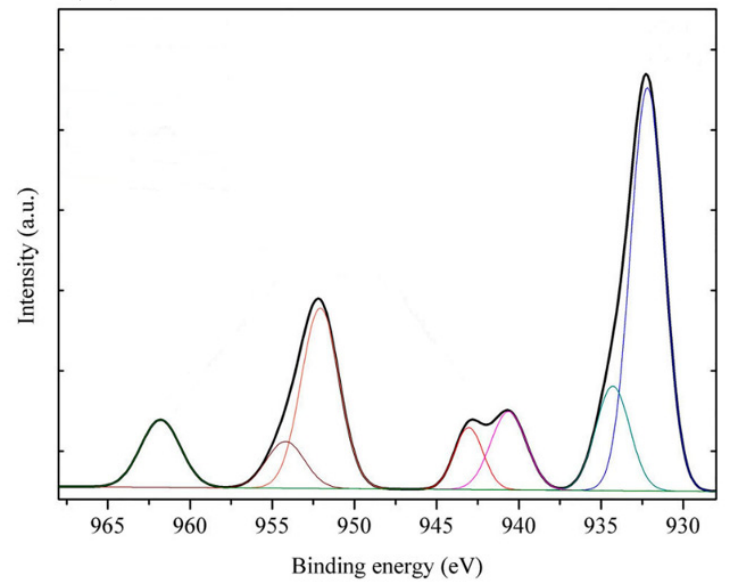

Figure 4. XPS spectra of $\mathrm{CuO}$ (a) before and (b) after the reaction; (temperature: $200{ }^{\circ} \mathrm{C}$; time: $1 \mathrm{~h} ; \mathrm{O}_{2}: 1 \mathrm{MPa}$; $\mathrm{CuO}: 1 \mathrm{mmol}$ )

The chemical functional group analysis for $\mathrm{CuO}$ were carried out by using FTIR spectrometer. As shown in Figure 5, the spectra indicated similar chemical identities of $\mathrm{CuO}$ samples before and after the oxidation reaction, as the peaks at $520 \mathrm{~cm}-1$ are both assigned to the $\mathrm{Cu}-\mathrm{O}$ stretching vibration. However, a high-intensity peak observed at $3300-3500 \mathrm{~cm}-1$ in the spectrum of the $\mathrm{CuO}$ after the reaction refers to the vibration of O-H bonds[19], 
demonstrating that hydroxyl radicals could be produced in the reaction system.

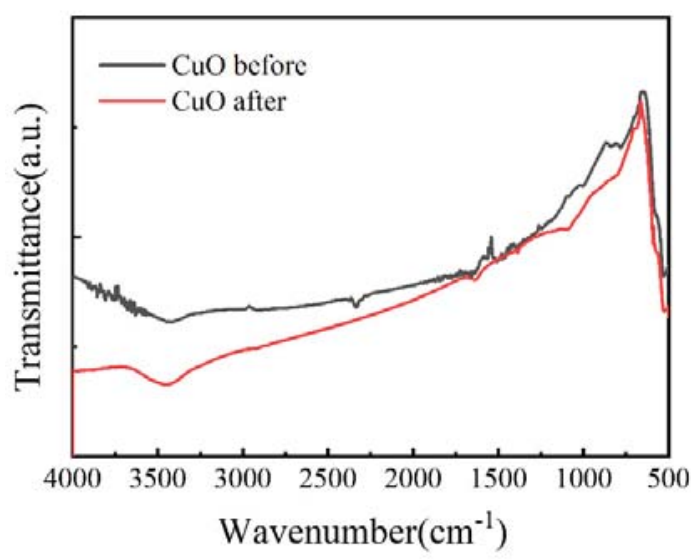

Figure 5. FTIR spectra of $\mathrm{CuO}$ before and after the reaction

\subsection{Catalytic wet air oxidation of 1,4-dioxane with CuO}

In general, temperature is a key factor in the application of catalytic wet air oxidation technology. Especially when oxygen used as an oxidant, the temperature dominates the overall reaction efficiency. In order to explore the appropriate reaction temperature, setting the temperature range was from 125 to $225 \mathrm{oC}$, and the results were shown in Figure 6. The increase of temperature has an obvious promoting effect in the reaction. The $\mathrm{R}$ of 1,4-dioxane increased by only $10 \%$ from $125 \mathrm{oC}$ to $150 \mathrm{oC}$. When the temperature rose from 150 to $200 \mathrm{oC}$, the $\mathrm{R}$ rapidly increased from 20 to $95.8 \%$, and the degradation reached $100 \%$ if the temperature continued to rise. However, from the perspective of energy utilization, it is not recommended to use excessive temperature for reaction, so $200 \mathrm{oC}$ is chosen as the appropriate reaction temperature. From the temperature range of the catalytic wet air oxidation technology $(150$ - 375 oC), the degradation of 1,4-dioxane by $\mathrm{CuO}$ is a mediumtemperature reaction and has an application prospect.

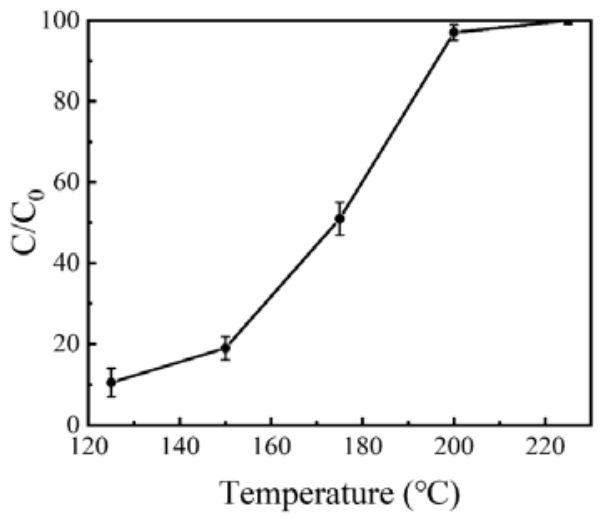

Figure 6. Effects of the reaction temperature on the degradation of 1,4-dioxane; (1,4-dioxane: $100 \mathrm{mg} / \mathrm{L}$; time: $1 \mathrm{~h}$; $\left.\mathrm{O}_{2}: 1 \mathrm{MPa} ; \mathrm{CuO}: 4 \mathrm{mmol}\right)$
Oxygen, as an oxidant, is also a crucial factor affecting the oxidation capacity of the reaction system and the removal rate of 1,4-dioxane. As shown in Figure 7, although the degradation of 1,4-dioxane can occur without the addition of $\mathrm{O} 2$, it could be greatly improved when a certain amount of $\mathrm{O} 2$ was added. When the oxygen pressure was $1 \mathrm{MPa}$, the removal rate got the best result, and there was no significant improvement effect when the oxygen pressure continued to increase. This indicates that $1 \mathrm{MPa}$ of oxygen will provide sufficient oxidation dose for the reaction system.

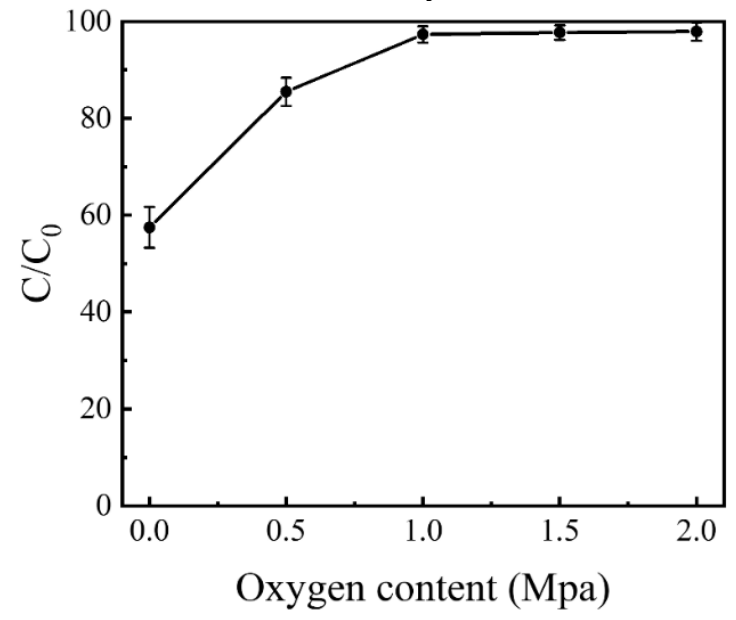

Figure 7. Effects of oxygen content on the degradation of 1,4dioxane; (1,4-dioxane: $100 \mathrm{mg} / \mathrm{L}$; temperature: $200{ }^{\circ} \mathrm{C}$; time: $60 \mathrm{~min}$; $\mathrm{CuO}: 5 \mathrm{mmol}$ )

The influence of the $\mathrm{CuO}$ amount toward the degradation of 1,4-dioxane can be seen in Figure 8. The addition of $\mathrm{CuO}$ promoted the reaction within a certain range. When the added amount was at the range of 4-6 mmol, the enhancement of $\mathrm{R}$ was not significant. However, when the added amount was more than $6 \mathrm{mmol}$, the continued addition of $\mathrm{CuO}$ resulted in a decrease of $\mathrm{R}$. The reason may be that the active sites increased and hence the reaction rates enhanced with the increasing $\mathrm{CuO}$ addition. However, exceeding $\mathrm{CuO}$ leaded to accumulation of catalysts, incurring the decrease of catalyst dispersion which resulting in the decrease of exposure of active sites, ultimately affecting the reaction efficiency.

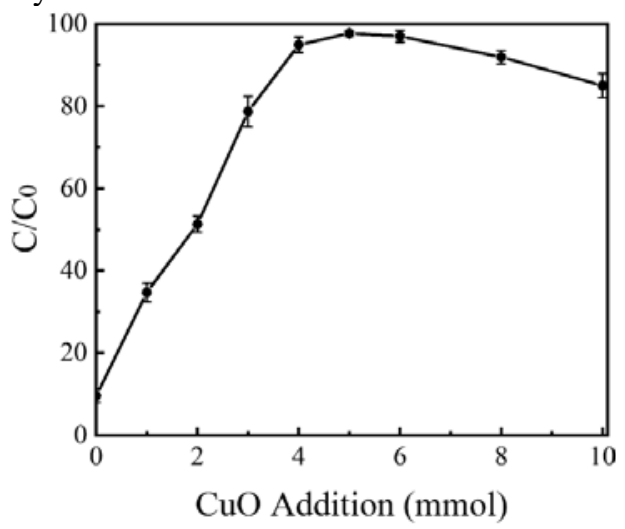

Figure 8. Effects of different $\mathrm{CuO}$ addition on the degradation of 1,4-dioxane; (1,4-dioxane: $100 \mathrm{mg} / \mathrm{L}$; temperature: $200^{\circ} \mathrm{C}$; time: $60 \mathrm{~min} ; \mathrm{O}_{2}: 1 \mathrm{MPa}$ ) 
With the increase of reaction time, the $\mathrm{R}$ of $1,4-$ dioxane was also continuously improved, as shown in Figure 9. The reaction rate rose slowly in the first $20 \mathrm{~min}$, then increased rapidly, and reached a high $\mathrm{R}$ of $95.8 \%$ at $60 \mathrm{~min}$. The removal efficiency of 1,4-dioxane was still increased for a long time, but the improvement effect was not obvious. Considering the removal effect and energy utilization, the optimal reaction time was selected to be 60 min.

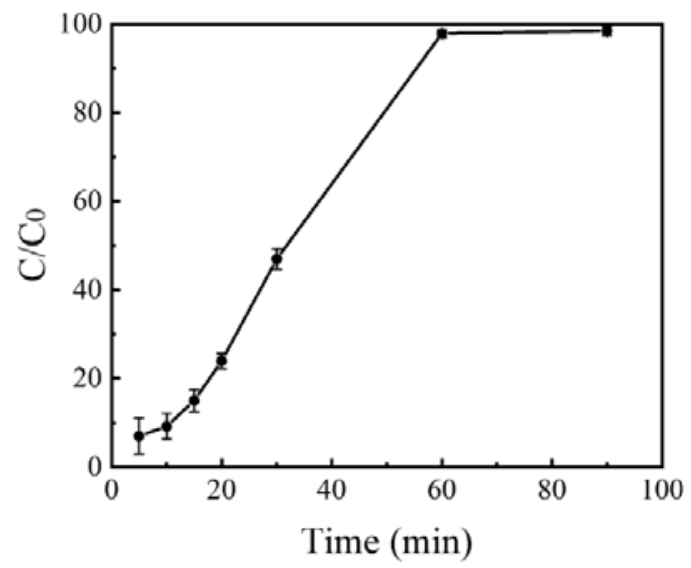

Figure 9. Effects of reaction time on the degradation of 1,4dioxane; (1,4-dioxane: $100 \mathrm{mg} / \mathrm{L}$; temperature: $200{ }^{\circ} \mathrm{C}$; $\mathrm{O}_{2}: 1$ $\mathrm{MPa}$; $\mathrm{CuO}: 5 \mathrm{mmol})$

In heterogeneous catalytic wet air oxidation, the role of the $\mathrm{pH}$ involves multiple aspects, including the decomposition of the oxygen molecules, the surface properties of the catalyst and the charge of ionizable organic molecules, which in turn affects the production of reactive oxygen species (ROS) and the degradation rate of water contaminants $[23,24]$. The effect of the initial $\mathrm{pH}$ on 1,4-dioxane degradation and mineralization under catalytic oxidation was investigated using $2 \mathrm{mmol}$ of $\mathrm{CuO}$. The results in Figure 10 show that the rate of 1,4-dioxane removal decreased rapidly as the $\mathrm{pH}$ increased and the rate of degradation was the highest at $\mathrm{pH} \mathrm{3}$, up to $99.8 \%$. The removal rate of 1,4-dioxane reached to $98.5 \%$ at $\mathrm{pH} 5$, but only $51 \%$ at $\mathrm{pH} 7$. Under alkaline conditions, the rate of 1,4-dioxane removal is less than $30 \%$. This indicates that acidic conditions are suitable for the reaction system, and the more $\mathrm{H}+$ in the solution, the easier it is for the ringopening degradation of 1,4-dioxane.

Then, the dissolution of $\mathrm{Cu} 2+$ in solution after different $\mathrm{pH}$ reactions was determined by inductively coupled plasma atomic emission spectrometry (ICP-AES). The results are shown in Table 1 , at $\mathrm{pH}=7$ and 9, only trace amount of $\mathrm{Cu} 2+$ was dissolved into the solution. However, under acidic conditions, there was a large amount of $\mathrm{Cu} 2+$ in the solution, especially under a strong acid condition at $\mathrm{pH}=3$, the dissolution of $\mathrm{Cu} 2+$ was as high as $7.231 \mathrm{mg} / \mathrm{L}$. It also reached $3.084 \mathrm{mg} / \mathrm{L}$ at $\mathrm{pH}=5$, which was hundreds of times of the amount of $\mathrm{Cu} 2+$ dissolved under neutral conditions. Although the dissolution of $\mathrm{Cu} 2+$ decreased slightly under the weakly alkaline condition of $\mathrm{pH}=9$, with the increase of alkalinity, the dissolution of $\mathrm{Cu} 2+$ in solution also increased continuously. Although strong acid conditions were conducive to the reaction, it might cause secondary pollution of water bodies.

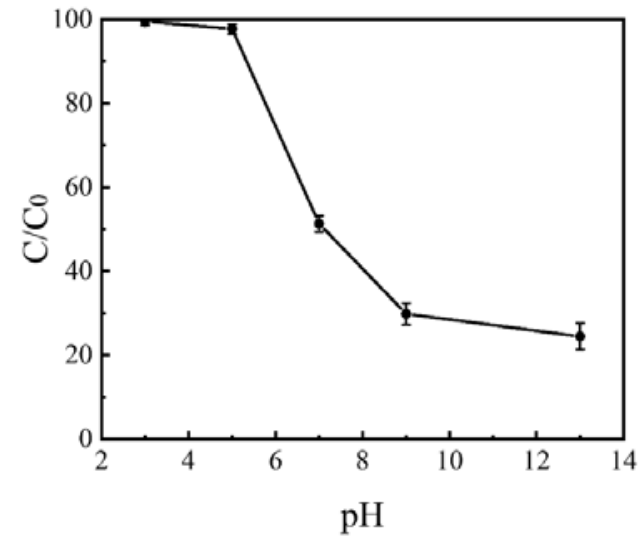

Figure 10. Effects of $\mathrm{pH}$ on the degradation of 1,4-dioxane; (1,4-dioxane: $100 \mathrm{mg} / \mathrm{L}$; temperature: $200{ }^{\circ} \mathrm{C}$; time: $60 \mathrm{~min}$; $\mathrm{O}_{2}: 1 \mathrm{MPa}$; $\mathrm{CuO}: 2 \mathrm{mmol}$ )

Table 1. The amount of $\mathrm{Cu}^{2+}$ dissolved in different $\mathrm{pH}$

\begin{tabular}{cc}
\hline sample & dissolution of $\mathbf{C u}^{\mathbf{2}}(\mathbf{m g} / \mathbf{L})$ \\
\hline $\mathrm{pH}=3$ & 7.2310 \\
$\mathrm{pH}=5$ & 3.0840 \\
$\mathrm{pH}=7$ & 0.0183 \\
$\mathrm{pH}=9$ & 0.0158 \\
$\mathrm{pH}=11$ & 0.6497 \\
\hline
\end{tabular}

The recyclability and stability of the catalyst are critical factors for the large-scale application of heterogeneous catalytic oxygen systems for water and wastewater treatment. In this study, the recyclability and stability of the $\mathrm{CuO}$ used in the treatment of 1,4-dioxane by catalyst oxygen were assessed during three consecutive reuse cycles. The catalytic activity of $\mathrm{CuO}$ during each cycle decreased slightly (Figure 11) but remained at acceptable values. The 1,4-dioxane removal efficiencies decreased from 95.8 to $76 \%$. The apparent loss of activity could result from the poisoning of the active sites, fouling of the catalyst surface by the reaction products, the loss of catalyst mass during each reusing cycle and copper leaching $[25,26]$.

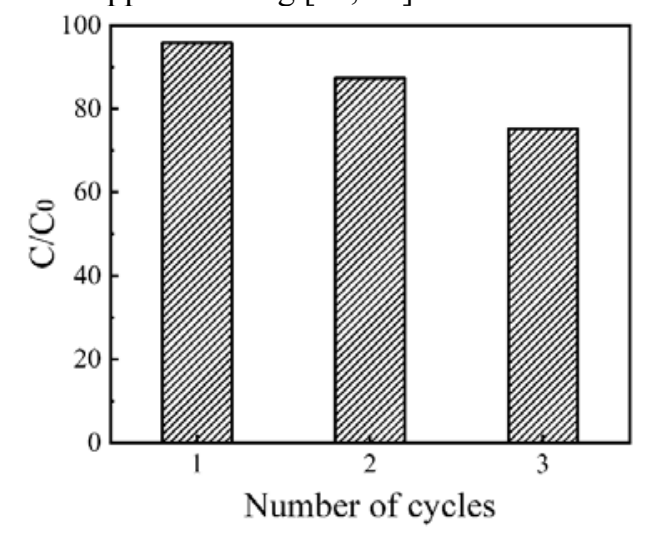

Figure 11. Effect of catalyst cycle times on removal rate of 1,4-dioxane; (1,4-dioxane: $100 \mathrm{mg} / \mathrm{L}$; temperature: $200{ }^{\circ} \mathrm{C}$; time: $60 \mathrm{~min} ; \mathrm{O}_{2}: 1 \mathrm{Mpa}$; $\left.\mathrm{CuO}: 5 \mathrm{mmol}\right)$

\section{CONCLUSIONS}

In summary, a CWAO process was introduced to degrade 
1,4-dioxane catalysed by $\mathrm{CuO}$ in this work. The highest removal rate of 1,4-dioxane was $95.8 \%$ when the optimal reaction conditions were $200 \mathrm{oC}$ and $1 \mathrm{MPa} \mathrm{O} 2$ for $60 \mathrm{~min}$ with $5 \mathrm{mmol} \mathrm{CuO}$ added. If the effect of $\mathrm{Cu} 2+$ dissolution was not considered, acidic conditions were suitable for $\mathrm{pH}=3$ with $2 \mathrm{mmol} \mathrm{CuO}$ added, the removal rate of 1,4dioxane was up to $99.8 \%$. Results indicated that CWAO with $\mathrm{CuO}$ showed promising performances on degradation 1,4-dioxane and it could be a potential way on disposition of all kinds of non-biodegradable organic wastewater.

\section{References}

1. A.C. Mcelroy, M.R. Hyman, and D.R.U. Knappe, 1,4-Dioxane in drinking water: emerging for 40 years and still unregulated. Current Opinion in Environmental Science \& Health. 7: p. 117-125 (2019)

2. A. Broughton, et al., 1,4-Dioxane: Emerging technologies for an emerging contaminant. Remediation. 29(4): p. 49-63 (2019)

3. M.G. Antoniou and H.R. Andersen, Comparison of UVC/S2O8(2-) with UVC/H2O2 in terms of efficiency and cost for the removal of micropollutants from groundwater. Chemosphere. 119 Suppl: p. S818 (2015)

4. B.J. Martijn, et al., Impact of IX-UF Pretreatment on the Feasibility of UV/H2O2Treatment for Degradation of NDMA and 1,4-Dioxane. Ozone: Science \& Engineering. 32(6): p. 383-390 (2010)

5. H.M. Coleman, et al., Degradation of 1,4-dioxane in water using $\mathrm{TiO} 2$ based photocatalytic and $\mathrm{H} 2 \mathrm{O} 2 / \mathrm{UV}$ processes. J Hazard Mater. 146(3): p. 496-501 (2007)

6. L. Zhao, et al., Degradation of 1,4-dioxane in water with heat-and $\mathrm{Fe}(2+)$-activated persulfate oxidation. Environ Sci Pollut Res Int. 21(12): p. 7457-65 (2014)

7. N. Kishimoto and H. Nishimura, Effect of $\mathrm{pH}$ and molar ratio of pollutant to oxidant on a photochemical advanced oxidation process using hypochlorite. Environ Technol. 36(19): p. 2436-42 (2015)

8. Z. Zhang, et al., Pilot-scale evaluation of oxidant speciation, 1,4-dioxane degradation and disinfection byproduct formation during UV/hydrogen peroxide, UV/free chlorine and UV/chloramines advanced oxidation process treatment for potable reuse. Water Res. 164: p. 114939 (2019)

9. S. Patton, et al., Impact of the Ultraviolet Photolysis of Monochloramine on 1,4-Dioxane Removal: New Insights into Potable Water Reuse. Environmental Science \& Technology Letters. 4(1): p. 26-30 (2016)

10. S. Chitra, et al., Degradation of 1,4-dioxane using advanced oxidation processes. Environ Sci Pollut Res Int. 19(3): p. 871-8 (2012)

11. A. Safarzadeh-Amiri, J.R. Bolton, and S.R. Cater, Ferrioxalate-mediated photodegradation of organic pollutants in contaminated water. Water Research. 31(4): p. 787-798 (1997)
12. W. Shen, et al., Kinetics and operational parameters for 1,4-dioxane degradation by the photoelectroperoxone process. Chem. Eng. J. 310: p. 249-258 (2017)

13. C.S. Lee, et al., Impact of groundwater quality and associated byproduct formation during UV/hydrogen peroxide treatment of 1,4-dioxane. Water Res. 173: p. 115534 (2020)

14. X. Xu, et al., Light-driven breakdown of 1,4-Dioxane for potable reuse: A review. Chem. Eng. J. 373: p. 508-518 (2019)

15. S.K. Bhargava, et al., Wet Oxidation and Catalytic Wet Oxidation. Ind. Eng. Chem. Res. 45(4): p. 12211258 (2006)

16. F. Arena, et al., Recent advances on wet air oxidation catalysts for treatment of industrial wastewaters. Inorganica Chimica Acta. 431: p. 101-109 (2015)

17. M.J. Dietrich, T.L. Randall, and P.J. Canney, Wet air oxidation of hazardous organics in wastewater. Environmental Progress. 4(3): p. 171-177 (1985)

18. Sushma, M. Kumari, and A.K. Saroha, Performance of various catalysts on treatment of refractory pollutants in industrial wastewater by catalytic wet air oxidation: A review. J. Environ. Manage. 228: p. 169-188 (2018)

19. A. Ananth, et al., Copper oxide nanomaterials: Synthesis, characterization and structure-specific antibacterial performance. Chem. Eng. J. 262: p. 179-188 (2015)

20. S. Anandan, G.J. Lee, and J.J. Wu, Sonochemical synthesis of $\mathrm{CuO}$ nanostructures with different morphology. Ultrason. Sonochem. 19(3): p. 682-6 (2012)

21. L.-J. Zhou, et al., Facile synthesis of highly stable and porous $\mathrm{Cu} 2 \mathrm{O} / \mathrm{CuO}$ cubes with enhanced gas sensing properties. Sensors Actuators B: Chem. 188: p. 533539 (2013)

22. G. Scaratti, et al., Treatment of aqueous solutions of 1,4-dioxane by ozonation and catalytic ozonation with copper oxide (CuO). Environ. Technol.: p. 1-13 (2018)

23. W. Chen, et al., Effective mineralization of Diclofenac by catalytic ozonation using Fe-MCM-41 catalyst. Chem. Eng. J. 304: p. 594-601 (2016)

24. Y. Huang, et al., Heterogeneous catalytic ozonation of dibutyl phthalate in aqueous solution in the presence of iron-loaded activated carbon. Chemosphere. 119: p. 295-301 (2015)

25. M. Ahmadi, et al., Catalytic ozonation of high saline petrochemical wastewater using PAC@Fe II Fe 2 III O 4 : Optimization, mechanisms and biodegradability studies. Sep. Purif. Technol. 177: p. 293-303 (2017)

26. D. Ranjbar Vakilabadi, et al., Catalytic potential of $\mathrm{Cu} / \mathrm{Mg} / \mathrm{Al}$-chitosan for ozonation of real landfill leachate. Process Saf. Environ. Prot. 107: p. 227-237 (2017) 